\title{
القيمة الفعلية للمطر والموازنة المائية في منطقة سرت
}

\section{د. التهامي مصطفى أبوغرسة}

جامعة مصراتة - كلية الآداب

\section{الملخص:}

تعد دراسة القيمة الفعلية للمطر، والموازنة المائية في منطقة الدراسة في غاية الأهمية نتيجة العلاقة القوية بين التوزيع الشهري للمطر خلال موسم المطر، والقيمة الفعلية للمطر أو معامل الجفاف، وضعف تلك العلاقة بانعدام فاعلية المطر خلال أشهر فصل الصيف الجاف. وكما أن كميات التبخر النتح الفعلي لمنطقة الدراسة، التي تتأثر برطوبة عالية نظراً لقربها من البحر فصل الشتاء حيث يمثل فائض مائي في الموازنة المائية، ويرجع ذلك إلى سقوط المطر وانخفاض درجة الحرارة، أم فصل الصيف الجاف يعاني من العجز المائي في الموازنة المائية يرجع ذلك إلى انقطاع المطر وارتفاع درجات الحرارة في المنطقة، حيث لا يوجد عامل مشجع للزراعة البعلية ومن الضروري استخدام الري، لا سيما عندما تكون الظروف الطبيعية وعمق التربة لا لا يسمح بالاحتفاظ بالمياه التي تم تخزينها أثناء موسم المطر.

\section{مقدمـة:}

إن أهمية المطر ليست أكثر من أهمية الانتفاع بها في التربة، وهذا المطر يمكن أن يتبخر

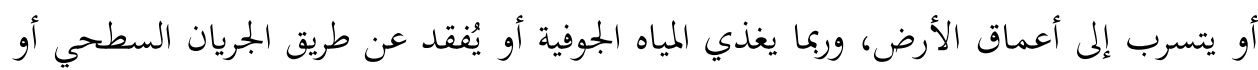
التبخر النتح الممكن، واحتمال الاحتفاظ بالماء في طبقة التربة بدون هطول متكرر يكون ضعيفاً

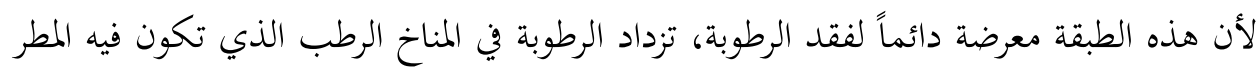
متوفر طول السنة وتقل الرطوبة في المناخ الجاف الذي يكون فيه المطر غير متوفر طول السنة. ويتوقف نشاط عمليات التبخر النتح على عوامل كثيرة يتعلق بعضها بعناصر المناخ نفسه، مثل درجة الحرارة، وشدة الرياح، ونسبة الرطوبة في الهواء ويتعلق بعضها الآخر بنوعية المطر وغزارته، وطبيعة الأرض التي تتعرض للمطر من حيث التكوين الجيولوجي والانحدار. 
أما الموازنة المائية تعتبر من المعايير المهمة لتحديد الاحتياجات المائية للمحاصيل الزراعية خاصة في المناطق التي تعاني من تباين وقلة المياه فيها كما هو الحال في منطقة الدراسة، ووفي الوقت نفسه تسعى الدولة الليبية لزراعة أكبر مساحة ممكنة من الأراضي بمواردها المائية المتاحة لتحقيق التنمية الزراعية لتأمين الغذاء لمواجهة التزايد السكاني المستمر. وتحاول هذه الدراسة الإجابة على بعض التساؤلات التالية:

ماهي القيمة الفعلية للمطر في منطقة الدراسة؟ وما نوع مناخها؟ وما درجة جفافها؟ وهل يوجد عجز أو فائض مائي خلال شهور السنة؟ وهل مياه المطر كافية لري المحاصيل الزراعية دون الاعتماد على الري؟ وما فاعلية المطر فيها؟ أهداف البحث: يهدف هذا البحث إلى الآتي:

1 1. الوقوف على انسب الطرق لقياس معامل الجفاف (القيمة الفعلية للمطر) والموازنة المائية، وأيضاً تحديد نوع المناخ السائد طوال السنة في منطقة الدراسة. 2. التعرف على الموازنة المائية في حالة العجز أو الفائض المائي فيما بين ما تحصل عليه المنطقة من خلال المطر، و ما تفقده عن طريق التبخر النتح الفعلي وعلى فاعلية المطر. 3. تحيد الاحتياجات المائية للمحاصيل الزراعية خاصة في المناطق التي تعاني من تباين المطر وقلة المياه فيها كما هو الحال في منطقة الدراسة . 4. التوصل إلى نتائج جيدة يمكن الاستفادة من خلالما في ججالات الحياة المختلفة.

\section{الدراسات السابقة: - ت ت}

لم يعثر الباحث على دراسة سابقة لذه الدراسة، إما أن تكون في معظمها جزءاً أو فصلاً في بعض دراسات الجغرافية المناخية أو الجغرافية الزراعية أو الهيدرولوجية أو المناخ الزراعي ومن بين هذه الدراسات مشكلة الأمطار في ليبيا ( شرف، 1963)(1)، وتناولت القيمة الفعلية

1- عبدالعزيز طريح شرف، جغرافية ليبيا، مطبعة المصري، الاسكندرية، مصر 1963،ص224. 
للأمطار، ودراسة البعثة اليوغسلافية لخصائص المطر و الجريان السطحي في منطقة جبل نفوسة

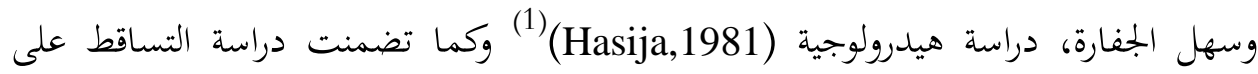
المرتفعات الشمالية الليبية، دراسة الموازنة المائية (حافظ،1996)(2) وكما تناولت أيضاً دراسة تقييم بعض المناطق المناخية في ليبيا ودورها في تحديد أولويات المناطق المروية والبعلية، دراسة

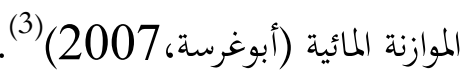

$$
\begin{aligned}
& \text { موقع منطقة الدراسة : }
\end{aligned}
$$

تمتد منطقة الدراسة من مدينة سرت إلى هراوة 75 كيلومتر شرقاً، وإلى وبويرات الحسون 85 كيلومتر غرباً، وإلى خشم اليهودي 85 كيلومتر جنوباً، أما فلكياً تقع بين دائرتي

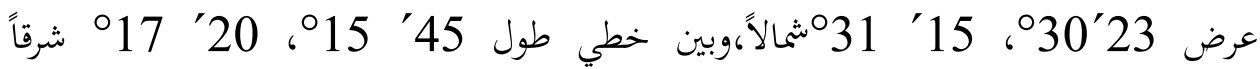
(شكل1) . إن اختيار منطقة سرت لإجراء هذه الدراسة كان اختيار موضوعياً مقبولاً وذلك للأسباب الآتية:

1. إن هذه المنطقة لم بحر عليها أي دراسة علمية على الموازنة المائية في السابق حسب علم الباحث. 2. مثل هذه الدراسة مهمة جداً عند وضع أية خطة للتنمية أو عند التخطيط الزراعي أو لتنفيذ أي مشروع من المشاريع، لأن ذلك يحقق عائدات اقتصادية كبيرة ويعود بالفائدة على المنطقة من جهة وعلى ليبيا من جهة أخرى .

1- Hasija S.C, The precipation - Run off chartocter of Jiffara- Nefusa Region, Tripoli, 1981.

2- ثُمَّمَ السيد حافظ، التساقط على المرتفعات الشمالية الليبية، رسالة ماجستير غير منشورة، جامعة

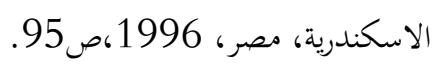

3- التهامي أبوغرسة، تقييم بعض المناطق المناخية في ليبيا ودورها في تحديد أولويات المناطق المروية والبعلية،

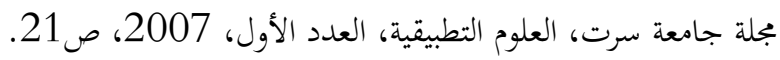




\section{مصادر البيانات:}

تم الحصول على البيانات المناخية لدرجات الحرارة وكميات المطر والتبخر لمدة 38 عاما من ( 1971-2009) محطة الأرصاد الجوية سرت، من قبل المركز الوطني للأرصاد الجوية - طرابلس، وهذه المحطة هي المططة الرئيسية والوحيدة في منطقة الدراسة، وتقع في مركز

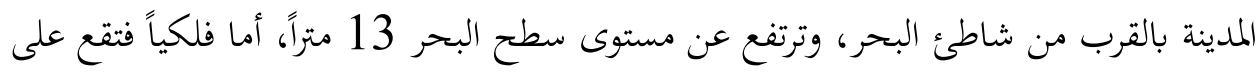

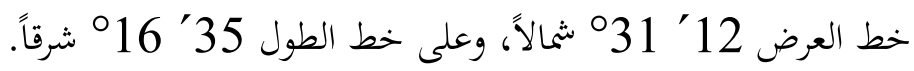

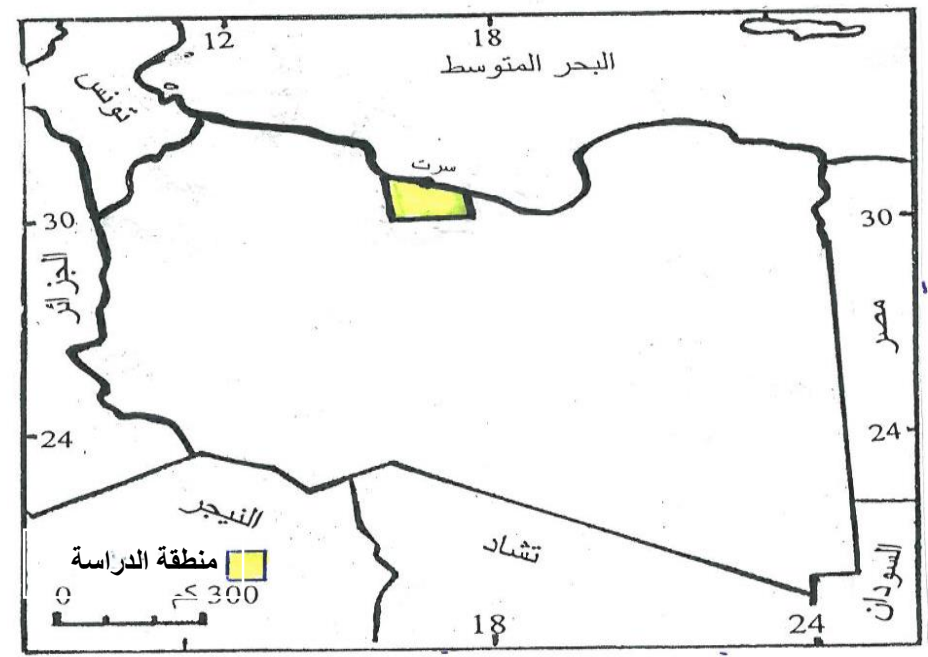

شكل (1) خريطة ليبيا مبيناً عليها منطقة الدراسة

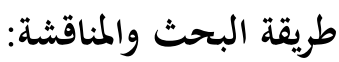

ولتحقيق بجموعة الأهداف السابقة من البحث وذلك بإتباع الاسلوب الكمي وتحويل الاحصاءات المناخية إلى أشكال بيانية وتحليلها تحليلاً دقيقاً، ودراسة المعاملات المناخية التي ولئي وضعها بعض الباحثين لتحديد القيمة الفعلية للمطر ولحساب الموازنة المائية، ومقارنة نتائجها وتطبيقاها على منطقة الدراسة. 


\section{أولاً: القيمة الفعلية للمطر:}

نظراً لأهمية القيمة الفعلية للمطر فقد حاول الكثير من علماء المناخ والنبات وعلم المياه

في ايجاد معاملات تُبنى على طرق رياضية لتقدير القيمة الفعلية للمطر، بهدف العلاقة بين التوزيع الجغرافي للنباتات والكفاية الفعلية للمطر. يعد ديمارتون (Demartoune) من أشهر الباحثين الذين اهتموا بمعرفة القيمة الفعلية

للأمطار عند دراسة المناخ وأثره على مظاهر الحياة المختلفة فوق سطح الأرض. ففي سنة 1925 رأى ديمارتون أن القيمة الفعلية للأمطار أو كما يسميها معامل الجفاف يمكن حساها بالمعادلة (شرف، 1971) (1) وهي كالآتي:

$$
\begin{gathered}
\frac{r}{10+\tau}=0 \\
\text { حيث إن }
\end{gathered}
$$

ق: القيمة الفعلية للأمطار أو معامل الجفاف

$$
\begin{aligned}
& \text { م: معدل المطر السنوي "ملم" } \\
& \text { ح: معامل درجة الحرارة السنوية (مº) } \\
& \text { 10: عامل ثابت }
\end{aligned}
$$

وعلى ضوء المعادلة السابقة وضع ديمارتون حدوداً معينة للأقاليم النباتية

$$
\text { والمناخية كما يتضح من الجدول الآتي: }
$$

\begin{tabular}{|c|c|}
\hline ق (القيمة الفعلية للأمطار أو معامل الجفاف) & 5 \\
\hline أقوع المناخ والحياة المناخية & المناخ جاف - صحراوي \\
\hline
\end{tabular}

1- عبدالعزيز طريح شرف، الجغرافيا المناخية والنباتية، دار الجامعة المصرية، الاسكندرية، 1971، 276،277 


\begin{tabular}{|c|c|}
\hline مناخ شبه جاف - أعشاب فقيرة & من 5 - \\
\hline مناخ رطب نسبيًّا - استبس "أعشاب قصيرة" & من 10 - \\
\hline مناخ رطب - حشائش غنية مختلط بالأشجار & من 20 - \\
\hline مناخ شديد الرطوبة - غابات & أكثر من 30 \\
\hline
\end{tabular}

وبتطبيق معادلة ديمارتون على منطقة الدارسة، وذلك باستخدام البيانات المناخية المبينة في الجدول (1)، حيث كمية المطر السنوية 207.0 ملليمتر والمتوسط السنوي لدرجة الحرارة 21.3 درجة مئوية.

$$
\text { فالقيمة الفعلية للأمطار أو معامل الجفاف ( ق) = } 6.6
$$

ومن هذه النتيجة يتضح أن مناخ منطقة سرت شبه جاف وبالإمكان تطبيق هذه

المعادلة على كل شهر على حدا ولكن في هذه الحالة علينا أن نضرب قيمة (ق) النابحة 12 حتى يمكن مقارنتها بالحدود المناخية العامة التي سبق ذكرها.

$12 \times \frac{r}{10+\tau}=$ على أن تصبح المعادلة على هذا النحو : ق

وبتطبيق هذه المعادلة ظهرت النتائج المبينة في الجلدول (1).

جدول (1) معاملات القيمة الفعلية للمطر في منطقة الدراسة طبقاً لمعادلة ديمارتون

\begin{tabular}{|c|c|c|c|c|}
\hline نوع المناخ والحياة النباتية & أقيمة الفعلية للمطر & لدمتوسط الشهري & المتوسط الشهري & الشهور \\
\hline رطب نسبيا & 20.4 & 14.1 & 41.0 & يناير \\
\hline رطب نسبيا & 10.4 & 14.7 & 21.5 & فبراير \\
\hline شبه جاف & 8.0 & 17.4 & 18.2 & مارس \\
\hline جاف صحراوي & 1.4 & 19.8 & 3.6 & أبريل \\
\hline جاف صحراوي & 1.3 & 22.1 & 3.5 & مايو \\
\hline جاف صحراوي & 0.2 & 24.4 & 0.6 & يونيه \\
\hline جاف صحراوي & 0.0 & 24.2 & 0.0 & يوليه \\
\hline جاف صحراوي & 0.0 & 28.0 & 0.0 & أغسطس \\
\hline
\end{tabular}




\begin{tabular}{|c|c|c|c|c|}
\hline جاف صحراوي & 0.3 & 27.2 & 10.8 & سبتمبر \\
\hline رطب نسبيا & 11.1 & 24.9 & 32.2 & أكتوبر \\
\hline رطب نسبيا & 11.2 & 19.7 & 27.6 & نوفمبر \\
\hline رطب & 22.3 & 15.8 & 48.0 & ديسمبر \\
\hline نوع المناخ & معامل الجفاف & المتوسط السنوي & المجموع السنوي & \\
\hline شبه جاف & 6.6 & $\left.{ }^{\circ}{ }^{\circ}\right) 21.3$ & 207.0 (ملم) & \\
\hline
\end{tabular}

- - المصدر: البيانات المناخية من المركز الوطني للأرصاد الجوية - طرابلس. - حسبت بيانات الجدول من قبل الباحث.

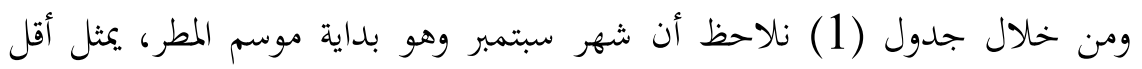
القيم عن باقي شهور موسم المطر أما شهر ديسمبر فيمثل أعلى قيم هذا المعدل إذ يصل إلى

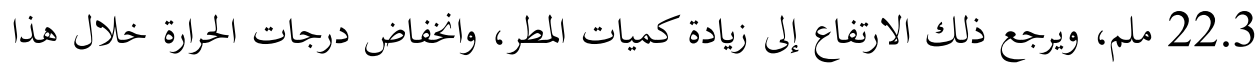
الشهر وتبدأ قيم المعامل في الانخفاض التدريجي في باقي شهور فصل الشتاء. ثم خلال شهري فصل الربيع (أبريل ومايو)، وذلك مع تناقص كميات المطر وارتفاع درجات الحرارة، حيث يتراوح

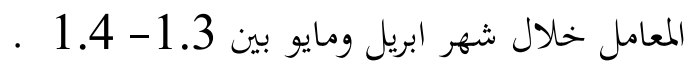
وفي عام 1957 أقترح عبدالعزيز طريح شرف في دراسة مقارنة أجراها لمعادلات القيمة الفعلية للمطر ومن ضمنها معادلتي كوين وديمارتون ومعادلة شرف المعدلة والتي سماها (متوسط المعادلات) وقد تميزت المعادلة ببساطتها التي تجعل من السهل تطبقها في الدراسات الجغرافية للمناخ ولقد وضع لها حدود مناخية مطابقة للحدود المناخية التي أقترحها ديمارتون، ومعادلة شرف (1) كالآتي:

$$
E=\frac{P}{T+9}
$$




$$
\text { = Sمية المطر السنوية أو الشهرية (ملم). P }
$$

المعدل السنوي أو الشهري لدرجة الحرارة (م) T T

$$
9
$$

وعن طريق هذه المعادلة يمكن معرفة القيمة الفعلية للمطر لكل شهر على حده

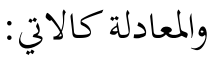

$$
E=\frac{P}{T+9} \times 12
$$

\begin{tabular}{|c|c|c|c|c|}
\hline نوع المناخ والحياة النباتية & أو معامل الجفيلية للمطر & 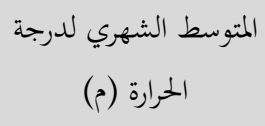 & المتوسط الشهري للمطر & الشهور \\
\hline رطب نسبيا & 21.3 & 14.1 & 41.0 & يناير \\
\hline رطب نسبيا & 10.9 & 14.7 & 21.5 & فبراير \\
\hline شبه جاف & 8.3 & 17.4 & 18.2 & مارس \\
\hline جاف، صحراوي & 1.5 & 19.8 & 3.6 & أبريل \\
\hline جاف- صحراوي & 1.3 & 22.1 & 3.5 & مايو \\
\hline جاف صحراوي & 0.2 & 24.4 & 0.6 & يونيه \\
\hline جاف صحراوي & 0.0 & 24.2 & 0.0 & يوليه \\
\hline جاف-صحراوي & 0.0 & 28.0 & 0.0 & أغسطس \\
\hline جاف-صحراوي & 3.6 & 27.2 & 10.8 & سبتمبر \\
\hline رطب نسبياً & 11.4 & 24.9 & 32.2 & أكتوبر \\
\hline رطب نسبياً & 11.5 & 19.7 & 27.6 & نوفمبر \\
\hline رطب & 23.2 & 15.8 & 48.0 & ديسمبر \\
\hline نوع المناخ & معامل الجفاف & المتوسط الشهري & البمموع السنوي & \\
\hline شبه جاف & 6.8 & 21.3 & 207 & \\
\hline
\end{tabular}

$$
\text { وبتطبيق هذه المعادلة فظهرت النتائج في الجدول (2). }
$$

جدول (2) معاملات القيمة الفعلية للمطر في منطقة الدراسة طبقاً لمعادلة شرف 
- - المصدر: البيانات المناخية من المركز الوطني للأرصاد الجوية - طرابلس.

$$
\text { - - بيانات الجدول من حساب الباحث. }
$$

أن مناخ منطقة سرت، شبه جاف، فإن التباين الزمني لمعامل الجفاف باختلاف أشهر السنة فنجد شهري أبريل ومايو يمثلان أقل القيم حيث يتراوح المعامل ما بين 1.3 - 1.5

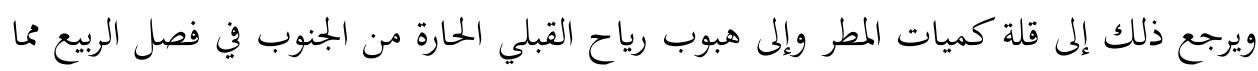
يؤدي إلى زيادة قيم التبخر، أما شهر ديسمبر فيمثل أعلى قيم المعامل حيث يصل إلى 23.2

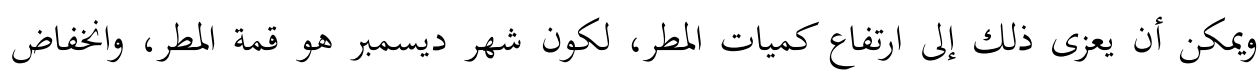
درجات الحرارة فيه، وتبدأ القيم على مستوى منطقة الدراسة في الانخفاض التدريجي خلال التهاع باقي

شهور فصل الشتاء حتى تصل إلى أقل معامل لها في هاية موسم المطر في شهر مايو 1.3. ومما سبق ومن خلال المقارنة بين نتائج المعاملين ديمارتون وشرف لإيجاد القيمة الفعلية

$$
\text { للمطر نستنتج ما يأتي: ومنا ومن }
$$

1. هناك علاقة قوية بين التوزيع الشهري للمطر خلال موسم المطر، والقيمة الفعلية للمطر وضعف تلك العلاقة بانعدام فاعلية المطر خلال أشهر فصل الصيف الجاف. 2. اختلاف القيمة العددية لفاعلية المطر في المعاملين ( ديمارتون وشرف) المستخدمين رغم تشابه أسس هذين العاملين في تحديد للقيمة المذكورة، ويرجع ذلك الاختلاف لتأثير العناصر المناخية كالحرارة، والتبخر والرطوبة النسبية في تحديد القيمة الفعلية للمطر، حيث

$$
\text { أظهرت نتائج المعادلتين أن منطقة سرت مناخها شبه جاف. ثافية }
$$

يقصد بالموازنة المائية مدى العلاقة بين كميات المطر، وكمية المياه المتبخرة من خلال دراسة مقارنة بينهما مع الاخذ في الاعتبار العوامل الأخر التي لما تأثير مباشر أو غير مباشر على فيلى قيم التبخر النتح والمطر. 
ولإيجاد الموازنة المائية في منطقة الدراسة اعتمد على كميات التبخر المقاسة بأنبوبة بيش لخطة الارصاد الجوية سرت وعلى كميات المطر لتحديد كمية العجز أو الفائض (Piche) المائي لكل شهر من شهور السنة ومن خلال تطبيق هذه الطريقة وكما هو مبين في الجدول وكانت النتائج على النحو الآتي:

يمثل فصل الشتاء أعلى معلات الفات الفائض المائي في الموازنة المائية حيث يصل إلى 42.3 ملم لشهر ديسمبر، وتقل معدلات الفائض المائي زمنياً بالانتقال من أشهر فصل الشتاء إلى شهر مارس، ثم يتحول في الشهرين الآخرين من فصل الربيع إلى معدلات نقص مائي وذلك نتيجة هبوب رياح القبلي الحارة من الجنوب التي تساعد على رفع قيم التبخر، ويستمر هذا النقص خلال شهور الصيف الجاف ليصل العجز المائي إلى - 7.8 ملم في شهر يوليه، ويرجع ذلك إلى انعدام المطر وارتفاع درجات الحرارة وما يصاحبها من ارتفاع في قيم التبخر، أما على مستوى شهور السنة فيمثل شهر ديسمبر أفضل الشهور لسنة الموازنة المائية، إذ يقل الفاقد بالتبخر ويسجل فائض مائي في منطقة الدراسة، ويلاحظ أن الفائض المائي يأخذ في التناقض خلال فصل الربيع ليصبح في شهر مارس 11.7 ملم، وتقل الأمطار خلال شهري ابريل ومايو ممائدي إلى عجز مائي، ويستمر هذا العجز المائي خلال شهور الصيف مع انقطاع المطر، ويصل العجز المائي أعلى معدل له بينما تأخذ معدلات الفائض المائي خلال شهور فصل الخريف في الزيادة، والتي تعتبر أشهر انتقال بين فصلي النقصان والزيادة في الموازنة المائية.

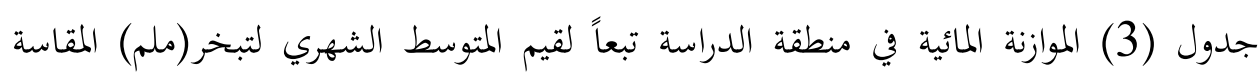
بأنبوبة بيش ومتوسط الشهري للمطر (ملم) خلال (1971 - 2009). 


\begin{tabular}{|c|c|c|c|c|c|c|}
\hline يونيه & مايو & أبريل & 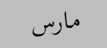 & فبراير & يناير ل & عناصر التوازن المائي \\
\hline 88.2 & 88.2 & 78.7 & 66.5 & 66.0 & 55.0 & التبخر \\
\hline 00.6 & 33.5 & 33.6 & 118.2 & 221.5 & 441.0 & التبخر \\
\hline $7.6--$ & $4.7--$ & $4.1--$ & $11.7++$ & $15.5++$ & $36.0++$ & أو الفائض المائي \\
\hline
\end{tabular}

\begin{tabular}{|c|c|c|c|c|c|c|c|}
\hline المجموع & ديسمبر & نوفمبر & أكتوربر & سبتمبر & أغسطس & يوليه & عناصر التوازن المائي \\
\hline 884.0 & 55.7 & 66.4 & 77.2 & 77.6 & 77.7 & 77.8 & التبخر \\
\hline 2207.0 & 448.0 & 227.6 & 332.2 & 110.8 & 00.0 & 00.0 & التبخر \\
\hline $123++$ & $42.3++$ & $21.2++$ & $25.0_{++}$ & $3.2++$ & 7.7-- & $7.8--$ & أو الفائض المائي \\
\hline
\end{tabular}

$$
\text { - - مبانات الجدر : البيانات المناخية من المركز الوطني للأرصاد الجوية - طرابلس من حساب الباحث. - }
$$

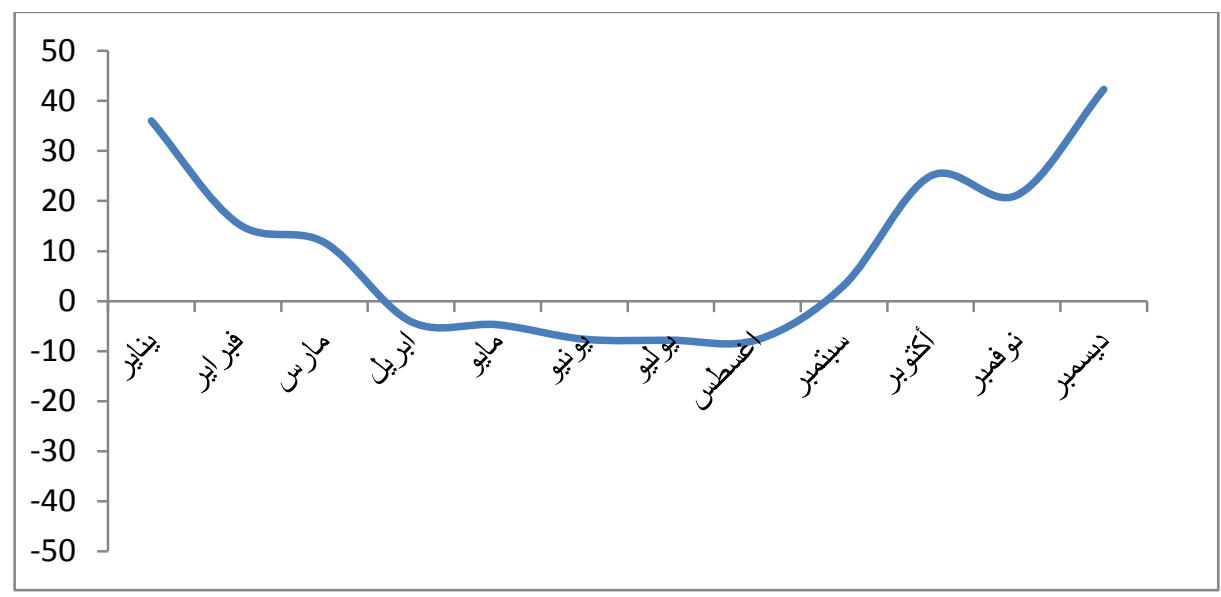

$$
\text { ملم }
$$


شكل (2) الفائض والعجز المائي في الموازنة المائية لمنطقة الدراسة تبعاً لقيم التبخر من

أنبوبة بيش والشكل يعتمد على بيانات الجدول (3).

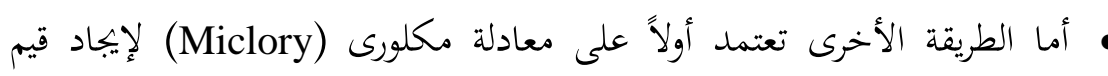

التبخر النتح الممكن (Abougharsa,1996) (1) فهي كالآي:

$\mathrm{ETP}=1.18 \times \mathrm{X}$

حيث إن ETP : التبخر النتح الممكن (ملم)

E

1.18

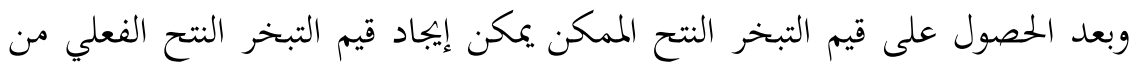

معادلة والين (Wallen) مُ و والمعادلة كالآين:

$\mathrm{ETA}=0.7$ X ETP

حيث إن: ETA = التبخر النتح الفعلي (ملم)

0.7

ETP

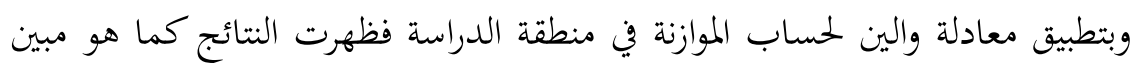

$$
\text { في الجدول (4) والشكل (3) وعلى النحو الآتي: }
$$

فصل الشتاء يمثل أعلى معدلات الفائض المائي في الموازنة المائية، حيث يصل إلى المى أعلى

قيمة 43.3 ملم في شهر ديسمبر، وتقل معدلات الفائض المائي زمنياً بالانتقال من أشهر فصل فئل

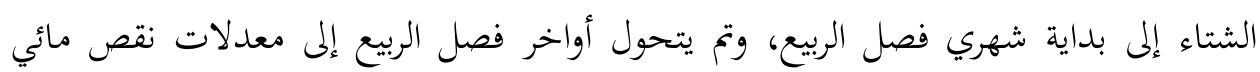
نتيجة هبوب رياح القبلي الحارة النقص خلال شهور الصيف الجاف حوالي -6.4 ملم في شهر لتهرل

1- Abougaharsa, T., Metrological Aspects Favoring Sustainable Development in Libya. Cairo University, 1996, p 56.

2- Wallen, C. , Study of Agroclimatology and Semi-Arid zones of the Near East, W.M.O, 1963. 
يوليو، ويرجع ذلك إلى انعدام المطر وارتفاع دراجات الحرارة، وما يصاحبها من ارتفاع في قيم التبخر .

أما على مستوى شهور السنة فيمثل شهر ديسمبر أفضل شهور السنة في الموازنة المائية في منطقة الدراسة، إذ يقل فيه الفاقد بالتبخر النتح الفعلي ويسجل فائض مائي، ويلاحظ أن الفائض المائي يأخذ في التناقص ليصبح في شهر مارس 12.8 ملم، ويتميز شهر أبريل بالعجز

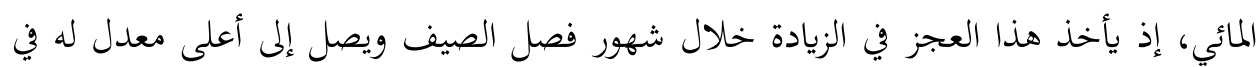
شهر يوليه في المنطقة، وذلك يرجع إلى انقطاع المطر، وارتفاع درجات الحرارة، بينما تقل معدلات العجز ا لمائي خلال فصل الخريف في شهر سبتمبر ويتم أخذ يأخذ الفائض المائي في الزيادة خلال شهور فصل الخريف، والتي تعتبر أشهر انتقال بين فصلي النقصان والزيادة تزداد معدلات الفائض في شهري أكتوبر ونوفمبر، والتي تعتبر أشهر انتقال بين فصلي النقصان والزيادة في الموازنة المائية.

جدول (4) الموازنة المائية لمنطقة الدراسة تبعاً لمعادلة والين لقياس التبخر النتح الفعلي (ملم)

\begin{tabular}{|c|c|c|c|c|c|c|}
\hline يونيه & 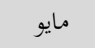 & أبريل أ & 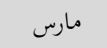 & فبراير & يناير & عناصر التوازن المائي \\
\hline 00.6 & 33.5 & 33.6 & 118.2 & 212.5 & 141.0 & المطر \\
\hline 99.7 & 99.7 & 99.1 & 77.1 & 77.1 & 15.9 & التبخر النتح الممكن \\
\hline 66.8 & 66.8 & 66.4 & 55.4 & 55.0 & 44.1 & التبخر النتح الفعلي \\
\hline$-6.2-$ & $-3.3-$ & $-2.8-$ & $12.8++$ & $+16.5+$ & $36.9++$ & العجز أو الفائض المائي \\
\hline
\end{tabular}

\begin{tabular}{|c|c|c|c|c|c|c|c|}
\hline البنموع & ديسمبر & نوفمبر & أكتوربر & سبتمبر & أغسطس & يوليه & عناصر التوازن المائي \\
\hline 2207.0 & 448.0 & 227.8 & 332.2 & 110.8 & 00.0 & 00.0 & المطر \\
\hline 999.3 & 66.7 & 77.6 & 88.5 & 99.0 & 99.1 & 99.2 & التبخر النتح الممكن \\
\hline 669.5 & 14.7 & 55.3 & 66.0 & 66.3 & 66.3 & 66.4 & التبخر التتح الفعلي \\
\hline$+162.5+$ & $+43.3+$ & $+22.3+$ & $+26.2+$ & $+4.5+$ & 6.3-- & $-6.4-$ & العجز أو الفائض \\
\hline
\end{tabular}

بيانات الجدول من عمل الباحث 


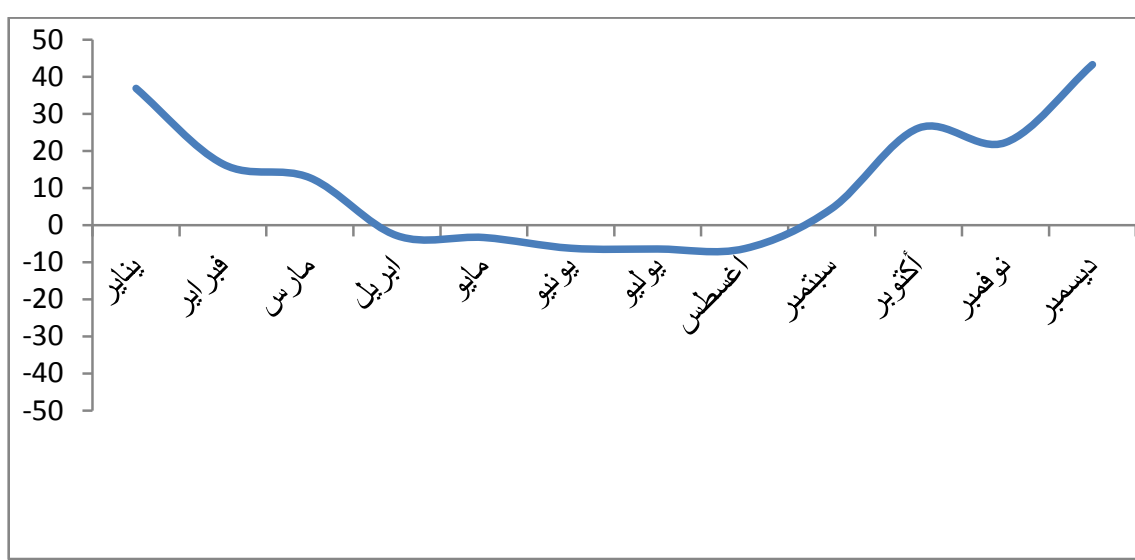

شكل (3) الفائض والعجز المائي في الموازنة المائية في منطقة الدراسة تبعاً لمعادلة والين

في قياس التبخر النتح الفعلي، اعتماداً على جدول (4). فاعلية ا لمطر في منطقة الدراسة:

من بيانات كمية المطر والتبخر و التبخر النتح وما يترتب على تلك العناصر من آثار في تحديد فاعلية المطر والموازنة المائية، يمكن القول بأنه لا يوجد فاعلية مطرية دائمة في منطقة الدراسة على أساس أن الجفاف يحدث عندما تكون كميات المياه المطلوبة للتبخر تزيد عن كمية

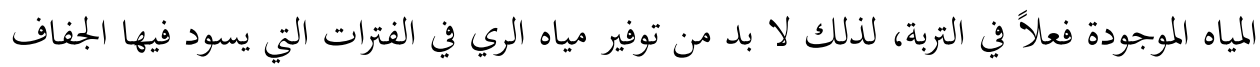
والا تعرض المحصول الزراعي للهاكك ويمكن القول أن المنطقة ذات فاعلية مطرية شبه دائمة

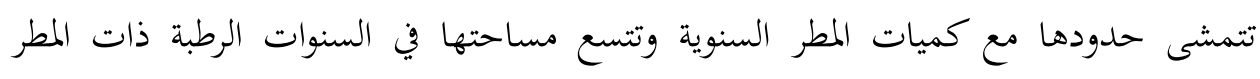
الغزير، وتتقلص في السنوات الجافة ذات المطر القليل وتباين المطر مما يؤثر بشكل واضح في الكفاءة الزراعية .

ففي سنوات المطر الغزير تكون المياه كافية لقيام الزراعة التي تعتمد على المطر بشكل

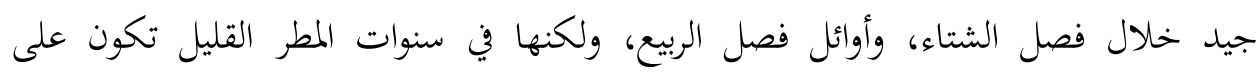

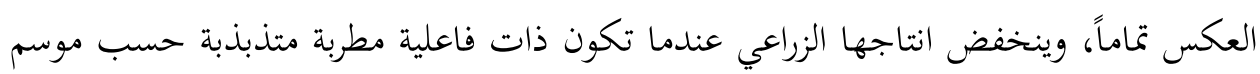
المطر ولذذا فهي تحتاج لمياه ري في شهور فصل الصيف الجاف. 


\section{نتنائج والتوصيات :}

محا سبق ومن خلال المقارنة بين الطرق والمعادلات السابقة لإيجاد القيمة الفعلية للمطر

ولحساب الموازنة المائية لمنطقة الدراسة نستنتج ما يأتي:

1 1. نتائج معادلتي (دمارتون وشرف) تظهر وجود تطابق في القيم الفعلية للمطر أو

معامل الجفاف لمنطقة الدراسة خلال شهور السنة، كما أوضحت النتائج أن مناخ المنطقة شبه

جاف.

2. توجد علاقة قوية بين التوزيع الشهري للمطر خلال موسم المطر، والقيمة الفعلية

للمطر وضعف تلك العلاقة بانعدام فاعلية المطر خلال أشهر فصل الصيف الجاف.

3. وجود تطابق إلى حد كبير بين نتائج الطريقة التي تعتمد على قيم التبخر من

أنبوبة بيشى وبين قيم التبخر النتح الفعلي المحسوبة عن طريقة معادلة والين الرياضية في تحديد شهور الفائض وشهور العجز المائي رغم اختلاف عناصر القياس بينهما بوجود قيم التبخر النتح في معادلة والين وعدم وجوده في طريقة التبخر (بيشى).

4. ومن خلال نتائج الطريقتين، فإن الموازنة المائية في فصل الشتاء تمثل فائض

مائي، أما في فصل الصيف يتمثل عجز مائي يرجع ذلك إلى انقطاع المطر وارتفاع درجات الحرارة والزيادة في قيم التبخر النتح، بينما تقل معدلات العجز المائي خلال شهور فصل الخريف، والتي تعتبر أشهر انتقال بين فصلي النقصان والزيادة في الموازنة المائية.

5.

زراعة المحاصيل الصيفية في هذه الفترة من السنة.

6. يمكن الاكتفاء باستصلاح الأراضي الجديدة في المناطق التي فيها التبخر النتح الممكن يساوي أو يقل عن 7 ملم - يوم في الموسم الأكثر جفافاً. 


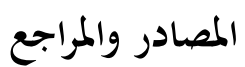

$$
\text { أولاً: العربية: - أبية }
$$

1- أبوغرسة، التهامي مصطفى، تقييم بعض المناطق المناخية في ليبيا ودورها في تحديد أولويات

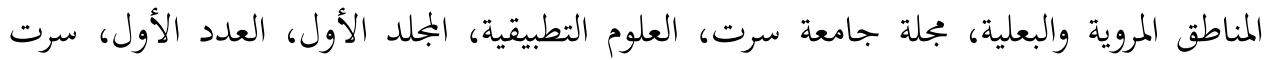
2007

$$
\text { 2- المركز الوطني للأرصاد الجوية، قسم المناخ، طرابلس. }
$$

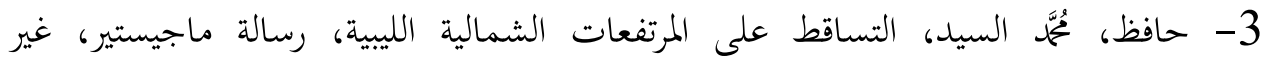
منشورة، جامعة الاسكندرية، مصر، 1996.

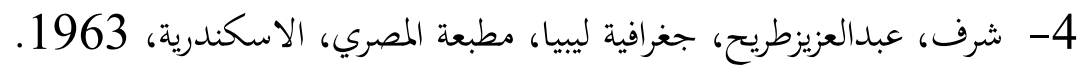

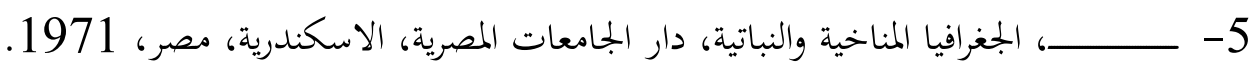

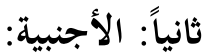

1- Abougharsa,T.(1996), Metrological Aspects Favoring Sustainable Development in Libya, Cairo University, Egypt.

2- Hasija, S.C.(1981), The Precipitation , Run off chartocter of Jiffara, Nefusa Region, Tripoli, Libya.

3- Wallen, C. (1963), Study of Agroclimatology and Semi-Arid zones of the Near East, W.M.O. 